\title{
Economic optimization of flood prevention systems in the Netherlands
}

\author{
Vana Tsimopoulou • Matthijs Kok • Johannes K. Vrijling
}

Received: 20 December 2013 / Accepted: 21 January 2015 / Published online: 14 February 2015

(C) The Author(s) 2015. This article is published with open access at Springerlink.com

\begin{abstract}
After the flood disaster of 1953, the Netherlands adopted a rational approach to flood risk management with the use of protection standards determined by means of costbenefit analysis. Due to scientific and political developments that have recently taken place, an update of the Dutch protection standards is being undertaken. One of the major priorities considered, is the need to address three issues, namely: (1) expressing the protection standards as failure probabilities of the flood defences, i.e. probabilities of breaching, instead of exceedance frequencies of water levels that is currently the case, (2) taking into account a spatial variability of those failure probabilities, and (3) considering various flooding scenarios. These aspects have been comprehensively addressed within a national flood risk analysis project, and partly considered in a numerical cost-benefit analysis approach, developed for the determination of new protection standards in the Netherlands. This paper presents an analytical economic optimization approach that makes an explicit link with all results of the national flood risk analysis project. In particular, an approach is outlined for the approximation of economically optimal design values of the failure probabilities along dyke-ring segments, which are treated as a series system of flood defences. The approach can assist in the determination of new protection standards in the Netherlands, but also in the design of flood prevention systems elsewhere.
\end{abstract}

Keywords Cost-benefit analysis $\cdot$ System reliability $\cdot$ Dyke-rings $\cdot$ Flood risk $\cdot$ Flood protection standards $\cdot$ Design specifications

\section{Introduction}

1.1 Context of the Dutch flood risk management policy

Modern societies are exposed to various types of hazards, which are responsible for thousands of human losses and severe economic damage every year. This has led many governments to

V. Tsimopoulou $(\triangle) \cdot$ M. Kok $\cdot$ J. K. Vrijling

Delft University of Technology, Stevinweg 1, 2600 AA Delft, The Netherlands

e-mail: vanatsimop@gmail.com

M. Kok

HKV Consultants, Lelystad, The Netherlands 
deal with them as risks that can be assessed and effectively reduced. As different people find different risk characteristics meaningful (Slovic 1999), safety regulations feature a variety of risk metrics (Bedford and Cooke 2001; Jonkman et al. 2003), ranging from individual risk to probability-weighted sums of non-linearly valued consequence types (Jongejan et al. 2012). These metrics can be utilised on the basis of different rationales, such as the precautionary principle (see, e.g. Barrieu and Sinclair-Desgagné 2006; Gollier and Treich 2003), risk-risk comparisons (see, e.g. Cassini 1998), or maximization of net economic benefits (see, e.g. Arrow et al. 1996; Pearce and Nash 1983).

The Netherlands has developed a flood risk management policy based on an economic rationale. After the flood disaster of 1953, when a large area of the south-western part of the country was flooded and more than 1800 people lost their lives (Gerritsen 2005), the so-called Delta Committee was installed by the government, whose main purpose was to coordinate actions towards a drastic reduction of flood risk. A key element of the Delta Committee's recommendations, which formed the foundation of the current flood risk management policy in the Netherlands, was the determination of protection standards for all major levee systems in the country defined in terms of exceedance frequencies of water levels, and derived by means of cost-benefit analysis. In that analysis as optimal protection level the one minimizing the total cost in the system during its lifetime was considered. This consisted of the cost of investment in the improvement of the flood defences and the expected losses after this improvement (Van Dantzig 1956), including human losses in monetary terms. The value of human losses was then determined based on estimated stock values of human capital (see, e.g. Petty 1690; Folloni and Vittadini 2010), while for future practices the method of valuation of statistical life and injuries (VOSL) is contemplated (Vrijling and Van Gelder 1997; Bockarjova et al. 2012). Other intangibles such as ecological and cultural consequences were not taken into account at the time, and although they can have a considerable effect on the results of the analysis, they are not explicitly tackled in this paper. The protection standards per dyke-ring were legally mandated in 1995 (Fig. 1).

Since significant investments of capital were required for the reduction of flood risk in the Netherlands of the 1950s, which included a shortening of the Dutch coastline of about $700 \mathrm{~km}$ with the closure of all major estuaries, it is reasonable that the Dutch decided to commit to an economic approach. Not balancing safety against its actual cost could have proven harmful for the national welfare. After the financial failure of Betuweroutea railway project in the 1990s that cost more than twice its initial budget, the use of cost-benefit analysis became mandatory for all public investments in the Netherlands (Huizinga 2012). This effectively means that the rationale adopted in the 1950 s is not likely to be substantially changed in the coming decades.

\subsection{Scope of this paper}

Despite the successful implementation of the recommendations of the Delta Committee, weaknesses have been identified in several parts of the approach for the determination of flood protection standards, and have been pointed out by Dutch experts in the field (e.g. Vrouwenvelder and Struik 1991; Jongejan 2008; Ten Brinke and Bannink 2004; Kind 2013). Acknowledging the need for improvements, the Dutch Government has initiated a process of revising the protection standards. Based on recommendations of the Second Delta Committee (2008) and the National Water Plan (2009), the priority points for revision have been set. Among others, three issues regarding the probabilities that are identified as protection standards are addressed. The first is that these probabilities refer to exceedance frequencies of water levels, which are directly related to the probabilities of overtopping. Overtopping is the event that the water level exceeds the crest level of the dyke, causing flooding in the protected area, and it is only one out of many failure modes of a dyke (see, e.g. Brandl and Szabo 2013). 


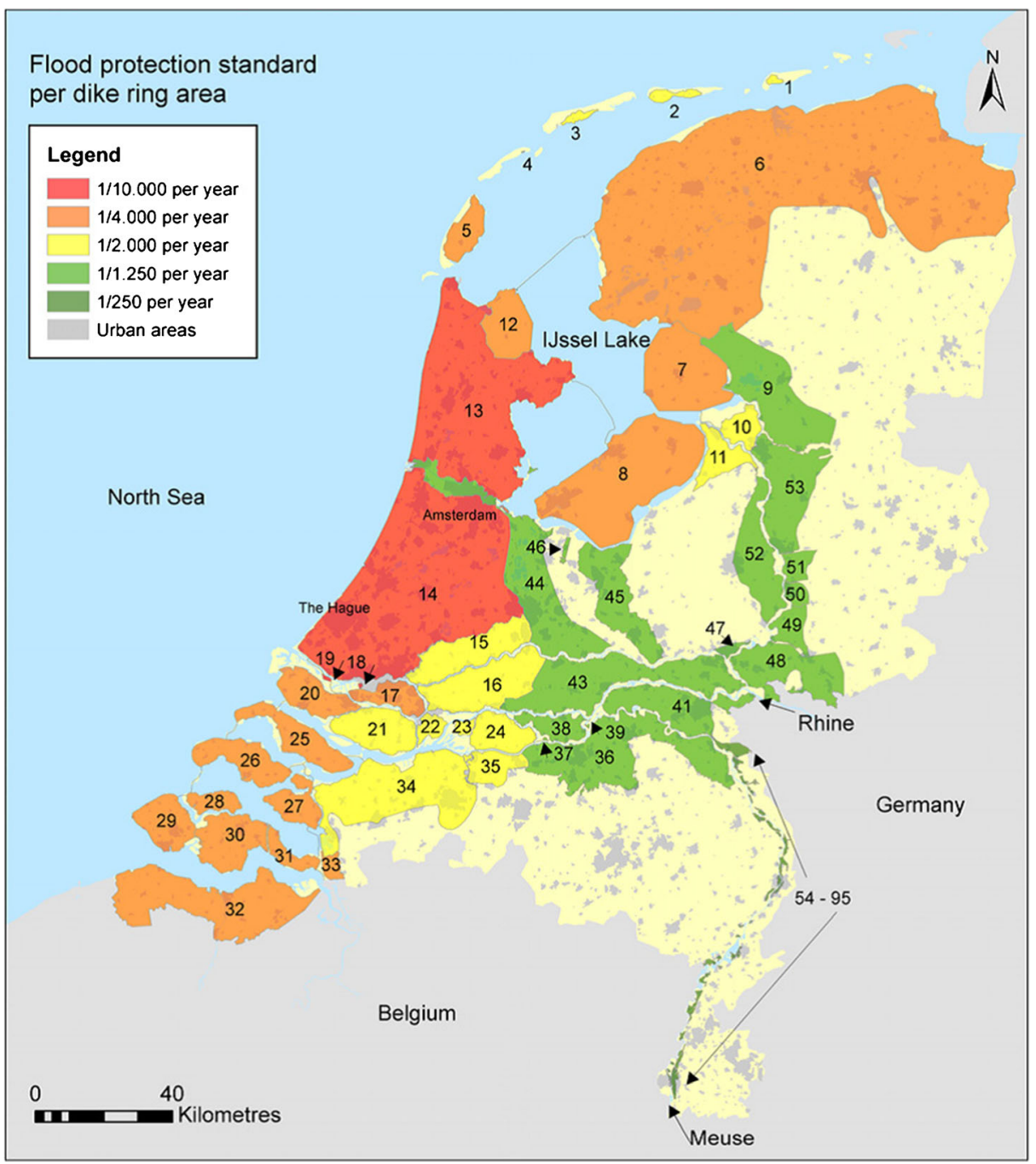

Fig. 1 Current flood protection standards in the Netherlands (Source: Ministry of Public Works, Water Management and Transportation of the Netherlands)

The real failure probability of a dyke is an aggregate value that depends on all failure modes. The second issue is that only one protection standard is assigned along the entire length of the dyke-ring. Yet, exceedance frequencies of water levels and other load and structural resistance properties can vary along this length, leading to a spatial variation of its actual failure probability. This affects the optimal level of protection, hence also the accuracy of the protection standards. The third issue is that the worst case scenario of damage is used in the economic optimization process. This means that in any flooding event total damage is considered to occur in the dyke-ring area, which is not the case. The above issues have already been addressed within a nationwide flood risk analysis project in the Netherlands, but only partly considered in a cost-benefit analysis model that is being contemplated for the determination of new protection standards (see also section 2). 
This paper presents an economic optimization for dyke-rings that addresses the three aforementioned issues. The basic objective is to introduce a procedure that can assist analysts in dealing with these issues, when opting for cost-efficient designs of flood prevention systems, within the scope of flood risk mitigation and adaptation strategies. In particular, an analytical approach is outlined for the approximation of economically optimal design values of the failure probabilities along dyke-rings. The dyke-ring is treated as a system of separate dyke-segments that may interact with each other. For every segment, a different design failure probability is assigned, i.e. a different protection standard. Depending on the desired level of accuracy and the availability of data, the analyst may decide along which length to assign one failure probability. In the Dutch case, choosing to derive one optimal failure probability per consequence-segment, i.e. a dyke-segment along which any failure induces the same consequences, a straightforward link with the results of the national risk analysis project is achieved.

\section{Recent developments in the Dutch flood risk management}

Within the past decade, some important scientific and political efforts took place in the Netherlands that set a strong basis for the formulation of a new flood risk management policy, and for the determination of new protection standards. The most important among them are summarized in this section.

\subsection{Flood risk analysis - the VNK2 project}

In 2006, the Dutch Ministry of Infrastructure and Environment, the Regional Water Authorities and Provincial Authorities took the initiative for a fully-probabilistic risk assessment of all major levee systems in the Netherlands (Jongejan and Maaskant 2013). This analysis was commissioned within the framework of the Flood Risk in the Netherlands 2 (VNK2) project (Veiligheid Nederland in Kaart or VNK2 in Dutch). In VNK2, a predefined procedure is used for the calculation of flood risk in any place in the Netherlands that is protected by flood defences. The flood defence system is divided in statistically homogeneous sections, and annual failure probabilities are calculated per section for each possible failure mechanism. Combining the probabilities of all failure mechanisms and homogeneous sections, the probabilities of occurrence of possible flooding scenarios are calculated. In each flooding scenario, consequences are estimated in terms of material damage and number of casualties. Based on failure probabilities and consequence estimates, various risk metrics are calculated. These include the total expected values and spatial distribution of economic damage and number of fatalities, the probabilities of floods with severe social consequences (i.e. societal risk), and the probabilities of death of individuals (i.e. individual risk). More information about the VNK2 project and the methods that are used within its framework can be found in relevant literature (e.g. VNK2 project office 2012; Jongejan et al. 2013; Jongejan and Maaskant 2013; Vrouwenvelder 2006; Van Manen and Brinkhuis 2005). The VNK2 project was completed in October 2014, and its results are now available to the Dutch public. Among the opportunities that the VNK2 offers for informed decision-making and future research is the possibility to incorporate its results in the procedures to derive new protection standards. These procedures comprise not only the economic optimization itself, but also the control of compliance of its results with individual and societal risk thresholds determined by the Dutch Government (Jonkman et al. 2011). In case of non-compliance, additional investments to those indicated by the economic optimization will need to be implemented. 


\subsection{Cost-benefit analysis - the OptimaliseRing model}

A cost-benefit analysis approach has been developed for the determination of new flood protection standards in the Netherlands. This approach comprises a dynamic economic optimization that indicates not only the optimal investment in dyke improvements, but also the optimal time intervals between consecutive investments (see, e.g. Vrijling and Van Beurden 1991; Eijgenraam 2005). A numerical model called OptimaliseRing has been developed in the Netherlands for the performance of this optimization, which was applied in all dyke-ring areas (Kind 2013). In that analysis, insights from VNK2 were used, leading to a successful transition from optimal exceedance frequencies of water levels to optimal failure probabilities, and incorporation of various damage scenarios. However, the model is less comprehensive with respect to spatial variability, as it considers a full correlation of failures along dyke-segments that can be hundreds of kilometres long. In order to reduce the effect of spatial variability, it has been recently suggested to determine protection standards along smaller dyke-stretches (see, e.g. Alberts et al. 2014). These dyke-stretches are optimized using the same principles as those of OptimaliseRing (Deltaprogramma 2013), which means that a full correlation of failures along their length is still considered.

\section{Failure of flood prevention systems}

Dyke-rings are systems of structures for the prevention of flooding. From a reliability engineering perspective, they are series flood protection systems. By definition, series systems fail if any one of their components fails (Joanni and Rackwitz 2008). In order to determine the failure probabilities of the dyke-ring components, which are here defined as probabilities of breaching, the hydraulic load events that they are subject to and their structural resistances need to be determined. In order to determine the risk of flooding in the dyke-ring area, the consequences associated with the failure of every dyke-segment need to be determined. This section provides some insight into the failure probabilities of dyke-segments, the consequences that they can induce, and how these determine the risk of flooding in the protected area.

\subsection{Failure probabilities of homogeneous sections}

The failure probability of a dyke-segment $i$ is the probability that its limit state function $Z_{i}$ becomes lower than zero:

$$
Z_{i}=R_{i}-S_{i}
$$

Where, $R_{i}=$ structural resistance of segment $i, S_{i}=$ hydraulic load on segment $i$. The values of hydraulic load and structural resistance usually depend on various variables. The probability distribution functions of those variables determine the probabilities of failure of dyke-segments.

A dyke-section along which load and resistance variables are described by a set of constant averages (Vrouwenvelder 2006), i.e. the failure probability is virtually identical along its length, constitutes a so-called homogeneous segment. The failure probability $P_{i}$ of such a segment depends on the failure mechanisms of the section and the degree of statistical correlation among them. Assuming that the occurrence of any failure mechanism leads to a breach, the failure probability of a homogeneous section for independent and dependent failure 
mechanisms is given in Table 1. For information on the failure probabilities of systems with parallel components or a mixture of series and parallel parts, see, e.g. Nowak and Collins (2000), or Kanning (2012).

In reality, the formulae in the table constitute an upper and a lower bound of the failure probability of the dyke-section, because the failure mechanisms can be partially correlated. This is due to the existence of common random variables in their limit state functions, e.g. hydraulic load variables and soil properties. A typical example of a correlation between failure mechanisms is the one between overtopping and piping, which both strongly depend on the water level (Sellmeijer 1988; Bligh 1915). The degree of correlation between different failure mechanisms can be described by means of appropriate correlation functions (see, e.g. Abrahamsen 1997). The correlation functions can be determined on the basis of measured data about load and structural resistance properties of dykes that failed or survived in the past (see, e.g. Schweckendiek and Kanning 2009), in combination with experts' judgements (see, e.g. Möllmann and Vermeer 2007). Since relevant data are usually scarce, experts' judgements are almost always necessary.

\subsection{Failure probabilities of heterogeneous segments}

The failure probabilities of longer, heterogeneous dyke-segments $k$ can be derived in a similar manner as the failure probabilities of homogeneous sections $i$. The formulae for dependent and independent sections $i$ are presented in Table 2. These equations refer to any type of serial components that can be present in a dyke-ring and not only to dyke-segments, such as stormsurge gates and sand dunes. They could therefore be applied in any series flood protection system for the calculation of its failure probability.

Due to imperfect correlations between homogeneous sections, the failure probabilities of Table 2 are again an upper and a lower bound. In particular, the correlation between the failures of two locations in a dyke-ring decreases as the distance between them increases. Consequently, the failure probability of a segment $k$ increases with its length (Schweckendiek et al. 2013).

\subsection{Consequence patterns}

In order to determine the risk of flooding associated with the failure of a dyke, the area that is affected by the failure and the resulting damage need to be determined. This determination can be done based on the results of flood simulations and land use data in line with the procedure followed in the Dutch VNK2 project. More specifically, the flood simulations can provide information on inundation depths, flow velocities and rise-rates, while the land use data indicate the economic value and population density in the dyke-ring area. The degree of damage and mortality can be estimated on the basis of dose-response functions (see, e.g. Jonkman 2007). The above-described procedure is a universal approach that could be used in any area protected by flood defence structures worldwide. How detailed and accurate such an analysis can be will always depend on the availability of relevant data. The Dutch have invested heavily in the acquisition of all information necessary for a detailed analysis, which is

Table 1 Failure probabilities of homogeneous dyke-sections $i$, where $m=$ number of failure mechanisms in segment $i$, and $P_{j}=$ probability of failure mechanism $j$
Independent failure mechanisms

$$
p=1-\prod_{j=1}^{m}\left(1-p_{j}\right)
$$

Fully dependent failure mechanisms $p=\max \left[p_{j}\right]$ 
Table 2 Failure probabilities of heterogeneous dyke-segments $\mathrm{k}$, where $h=$ number of homogeneous sections $i$ in a heterogeneous dykesegment $k$

$$
\text { Independent sections i } \quad p_{k}=1-\prod_{i=1}^{h}\left(1-p_{i}\right)
$$

Fully dependent sections $i$

not the case in the majority of countries with flood-prone areas. In order to apply the same procedure in other countries, experts' judgements on missing data may be necessary.

The consequences of a dyke breach can vary depending on properties of the loading event (e.g. water level; duration of loading), and on how the breach develops over time. These parameters affect the flooding properties, i.e. the inundation depths, flow velocities, etc. In this analysis, a constant value of the total consequences per dyke-segment breach is considered, which represents a weighted average of all existing loading scenarios that can induce breaching.

The spatial distribution of consequences can also vary, depending on the morphology of the protected area. If the dyke system protects a very small and relatively flat area, breaching of any section $i$ within a dyke system may lead to identical distribution of consequences in space. If there are secondary dykes, the spatial distribution of losses is different when they fail. The effect of secondary dykes is not taken into account explicitly in this paper, but it is assumed that their failure or non-failure can be considered as a separate inundation scenario that can be taken into account in a weighted average of the consequences.

The consequence patterns that can occur after the breaching of different sections $i$ within a dyke-segment $k$ can be classified in three categories: (1) identical consequences, (2) overlapping consequences, and (3) non-overlapping consequences (Fig. 2). The superposition of consequences due to breaching of different dyke-sections is shown in the final row.

\subsection{Flood risk}

By combining failure probabilities with consequence patterns, the risk of flooding can be calculated. The risk formulae given independence and dependence of the homogeneous segments i, are presented in Table 3.

\section{Economic optimization of a fictitious dyke-ring}

In this section, the above-presented theory is used for the economic optimization of a fictitious dyke-ring that consists of two homogeneous sections $i$. The purpose of this example is to show the principles of an economic optimization in simple series flood protection systems, which is important for understanding the optimization of real dyke-rings that is introduced later on in this paper. The fictitious dyke-ring is optimized for the cases in which the failures of its sections are either statistically every case three sub-cases are studied, which refer to the three types of consequence patterns. Such a dyke-ring constitutes a simplified version of the real dyke-rings. For this case, Fig. 2 is reduced to the schematization of Fig. 3, dependent or statistically independent.

The analysis refers to a planning period of $t_{\mathrm{p}}$ years, and assumes that investments are only made at $t=0$. Throughout the planning period an increase of the hydraulic load due to climate change is considered, as well as a constant economic growth. The outcome of the analysis is the optimal failure probabilities of the two segments per year, for which the total cost throughout lifetime is minimized. 


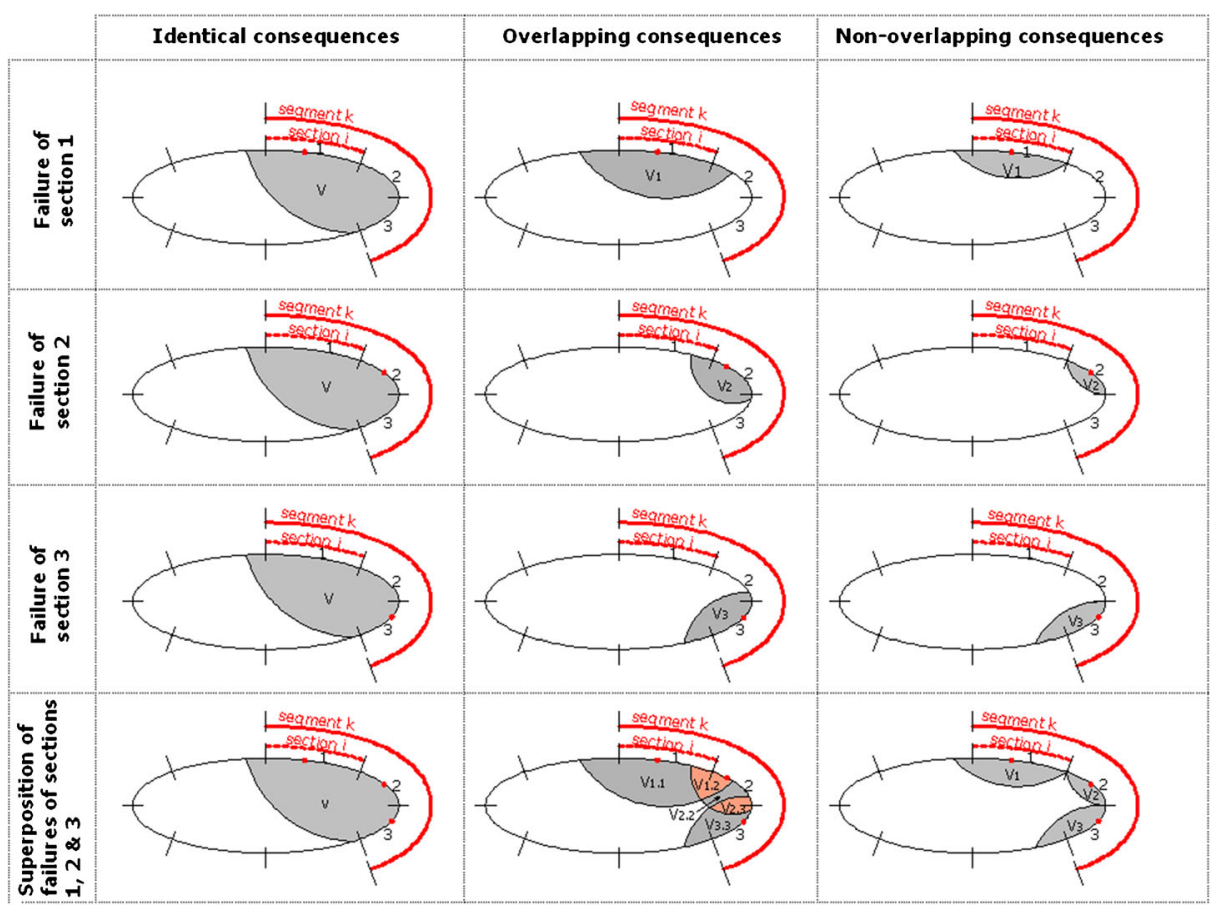

Fig. 2 Consequence patterns due to failure of segment with multiple homogeneous sections (read column-wise)

\subsection{Total cost function}

The total cost in the system throughout lifetime is given by the following equation:

$$
T C=\sum_{i=1}^{2} I_{i}+P V(R)
$$

Where, $I_{\mathrm{i}}=$ investment cost for improvement of section $i, R=$ sum of annual expected losses in the dyke-ring in a time period $t_{\mathrm{p}}$, and $\mathrm{PV}=$ present value operator.

Table 3 Risk of flooding associated with the failure of heterogeneous dyke-segments, where $h=$ number of homogeneous dyke-sections $i$ in a segment $k$ with $h \geq 2, P_{i}=$ failure probability of section $i, V=$ losses due to failure of any section $i$ (Fig. 2a), $V_{i . i}=$ losses in area affected only by failure in section $i$ (Fig. 2b), $V_{i . i+1}=$ losses in area affected by failures in both section $i$ and $i+1$ (Fig. 2b), $V_{i}=$ damage induced by failure in section $i$ (Fig. 2c)

Dependent sections i

$\max \left\{p_{i}\right\} \cdot V$

Identical consequences

Overlapping consequences

Non-overlapping consequences
Independent sections $\mathrm{i}$

$$
\left[1-\prod_{i=1}^{h}\left(1-p_{i}\right)\right] \cdot V
$$

$$
\max \left\{p_{i}\right\}\left(\sum_{i=1}^{h} V_{i}+\sum_{i=1}^{h-1} V_{i . i+1}\right) \quad \sum_{i=1}^{h} p_{i} V_{i . i}+\sum_{i=1}^{h-1}\left[\left(p_{i}+p_{i+1}-p_{i} p_{i+1}\right) \cdot V_{i, i+1}\right]
$$

$\max \left\{p_{i}\right\} \cdot \sum_{i=1}^{h} V_{i}$ 


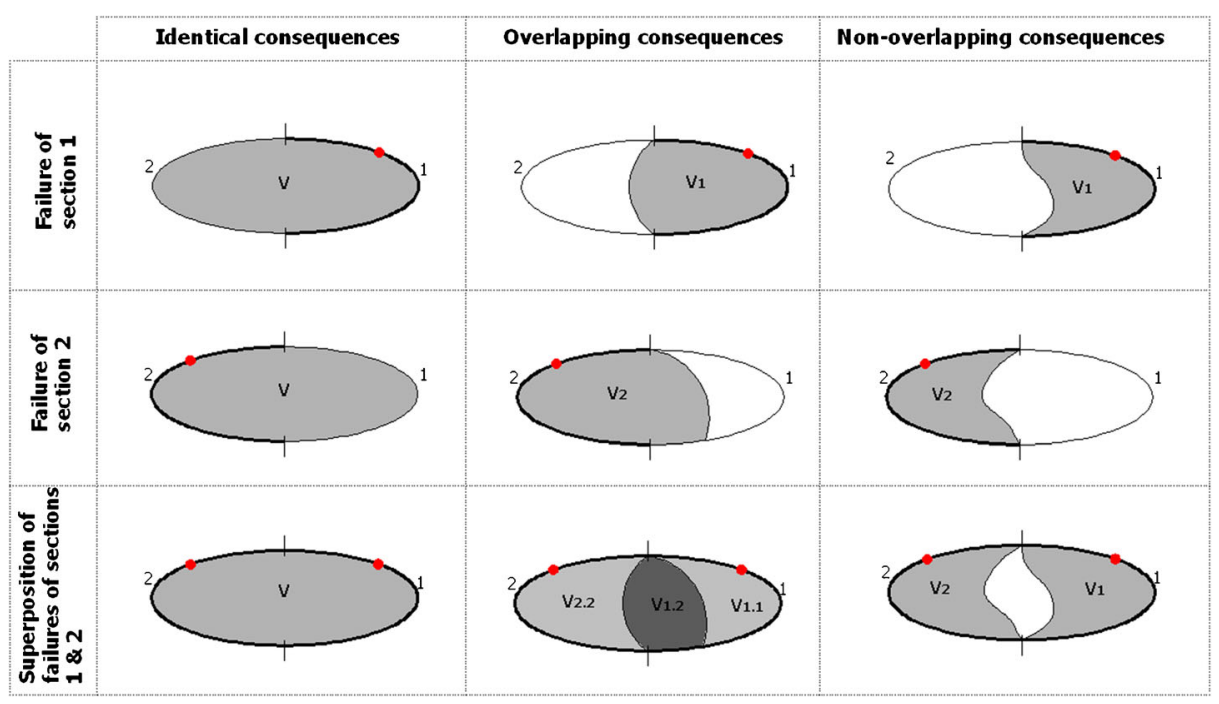

Fig. 3 Overview of studied cases

The cost of investment in a dyke-segment $i\left(I_{i}\right)$ can be approximated with a logarithmic function of its failure probability $\left(P_{i}\right)$. Modelling the investment cost as a function of the failure probability is an approach that has been presented in detail by Voortman (2003). In this method, the costs of measures against different failure mechanisms, and the degree that they reduce the failure probability of dyke-segments, are explicitly taken into account. This approach greatly facilitates our analysis, as it allows expressing the total cost as a function of the failure probabilities of dyke-segments. The choice of a logarithmic correlation between investment cost and failure probability is based on the fact that failure probabilities are highly correlated to the water levels (see, e.g. Bischiniotis 2013; Tsimopoulou 2010), whose frequency can be well described by extreme value distributions, including the exponential distribution (Walton 2000; Gumbel 1954). A prerequisite for such a logarithmic correlation is that the investment cost increases linearly with the increase of the crest level of the dyke. This is a working assumption that facilitates an analytical solution to the optimization problem. A more accurate cost function requires that the optimization problem be solved numerically. In any case, the effect of this assumption on the final result can be tested by means of sensitivity analyses. The investment cost function of a segment $i$ can be written as follows:

$$
I_{i}=-a_{i} \ln P_{i}+b_{i}
$$

Parameter $a_{i}$ expresses the marginal variation of the investment cost for a marginal decrease of the failure probability and it is by definition positive. Parameter $b_{i}$ has no physical meaning, as it represents the value of $I_{i}$ for which the failure probability is equal to one. Following a simple algebraic reasoning, parameter $b_{i}$ proves to always be negative. The above investment function is only valid for values of $P_{i}$ that are smaller than the failure probabilities of the dykes today $\left(P_{0 . i}\right)$. It is noted that the investment function is stationary. This means that $P_{i}$ and $P_{i .0}$ refer to the failure probabilities of the dykes at $t=0$.

An example of this type of investment cost functions is presented in Fig. 4. The curves refer to the sea dykes of Ommelander and the Eems Harbour in the province of Groningen in the 


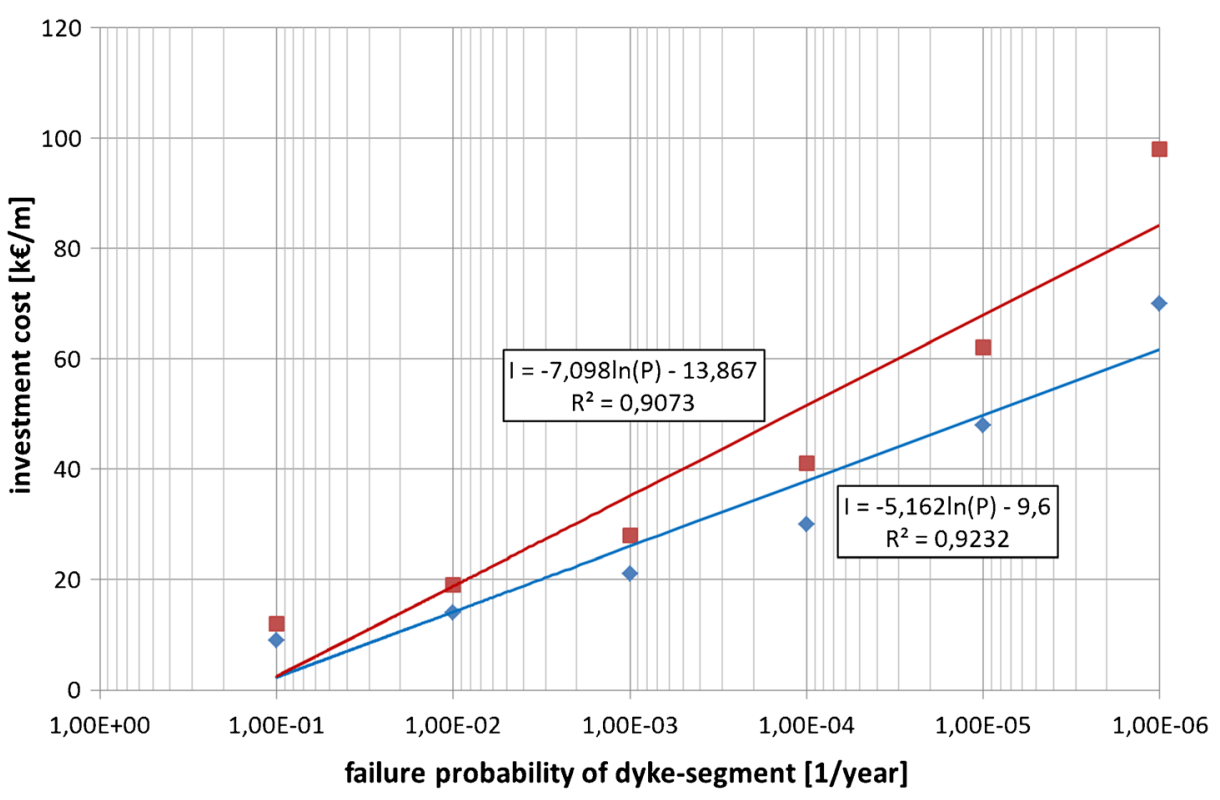

^ Ommelander Eemshaven — Log. (Ommelander) — Log. (Eemshaven)

Fig. 4 Investment cost per unit length of dyke-segments in Ommelander and Eems Harbour as a function of their annual failure probability (data source: Voortman 2003)

Netherlands, which have been fit to data derived by Voortman (2003), using the method of least squares. The used data concern the correlation between investment costs and failure probabilities of the two dyke-stretches.

The expected losses in a dyke-ring can be expressed as:

$$
P V(R)=\sum_{t=0}^{t_{p}} P_{t} V_{t}
$$

Where $t_{\mathrm{p}}=$ lifetime of the investment, $P_{t}=$ failure probability of the dyke-ring in year $t, V_{t}=$ discounted losses due to failure in year $t$.

Throughout the lifetime of the system, the reliability of the dyke-ring areas decreases due to the joint effect of climate change and structural deterioration. The combination of increased water levels due to climate change, and subsidence of the subsoil determines the increase of the annual probability of water level, which is the variable with the highest effect in the annual failure probability of a dyke-segment. For this reason, the failure probability of the system in year $t$ is calculated taking into account the joint effect of increased water levels and subsidence only, according to the following equation:

$$
P_{t}=P_{0} e^{\overline{\alpha \eta} t}
$$

Where, $P_{0}=$ failure probability of the dyke-ring at $t=0, \bar{\alpha}=$ weighted average of the scale parameters of the exponential distributions that the relative increase of water 
level follows, $\bar{\eta}=$ weighted average of annual increases of water level reduced by the effect of subsidence of the subsoil [cm/year]. The weighted averages are calculated as follows:

$$
\begin{gathered}
\bar{\alpha}=\sum_{i=1}^{2} \frac{\alpha_{i} L_{i}}{L} \\
\bar{\eta}=\sum_{i=1}^{2} \frac{\eta_{i} L_{i}}{L}
\end{gathered}
$$

Where, $L_{i}=$ length of segment $i, L=$ total length of the dyke-ring, $\alpha_{i}=$ scale parameter of the exponential distribution of water levels in front of segment $i, \eta_{i}=$ relative increase of water level in front of segment $i$.

The economic value of the protected area increases over time too, due to economic growth. The losses due to failure of the system in year $t$ are given by the following equations:

$$
V_{t}=V_{0}\left(\frac{e^{\gamma}}{1+r}\right)^{t}
$$

Where, $V_{0}=$ economic losses induced by the failure at $t=0, \gamma=$ annual economic growth, and $r=$ annual discount rate.

For a dyke-ring in the Netherlands, the economic losses taken into account in Eq. 8 refer to the sum of the estimated economic value of material assets in the flooded area, the estimated indirect losses caused by the interruption of business activities due to flooding, and the value of human life expressed in monetary terms.

Substituting Eqs. 5 and 8 into Eq. 4, the expected losses in the system become:

$$
\operatorname{PV}(R)=R_{0} \tau
$$

Where, $R_{0}=$ risk in the system at $t=0$, and $\tau=$ present value multiplier:

$$
\begin{gathered}
R_{0}=P_{0} V_{0} \\
\tau=\sum_{t=0}^{t_{p}}\left(\frac{e^{\bar{\alpha} \bar{\eta}+\gamma}}{1+r}\right)^{t}
\end{gathered}
$$

\subsection{Optimal failure probabilities}

The failure probabilities $P_{1}$ and $P_{2}$ of the segments that minimize the total cost function (Eq. 2) can be derived through a second derivative test (Stewart 2008). First, the critical points of the cost function need to be found, which are those satisfying the following condition:

$$
\left.\begin{array}{l}
\frac{\partial T C}{\partial P_{1}}=0 \\
\frac{\partial T C}{\partial P_{2}}=0
\end{array}\right\} \Leftrightarrow\left(P_{1}, P_{2}\right)=\left(P_{1 . c r}, P_{2 . c r}\right)
$$


In order for a critical point $\left(P_{1 . \mathrm{cr}}, P_{2 . \mathrm{cr}}\right)$ to minimize the total cost function, i.e. to be the optimal solution, the following conditions need to be satisfied:

$$
\left.\begin{array}{c}
\frac{\partial^{2} T C}{\partial P_{1}{ }^{2}}\left(P_{1 . c r}, P_{2 . c r}\right)>0 \\
\frac{\partial^{2} T C}{\partial P_{2}{ }^{2}}\left(P_{1 . c r}, P_{2 . c r}\right)>0 \\
\frac{\partial^{2} T C}{\partial P_{1}{ }^{2}}\left(P_{1 . c r}, P_{2 . c r}\right) \cdot \frac{\partial^{2} T C}{\partial P_{2}{ }^{2}}\left(P_{1 . c r}, P_{2 . c r}\right)-\frac{\partial^{2} T C}{\partial P_{1} \partial P_{2}}\left(P_{1 . c r}, P_{2 . c r}\right)>0
\end{array}\right\}
$$

For dyke-rings with more than two segments, optimal failure probabilities can also be derived analytically following a similar procedure. In those cases, the optimal solution is found again among the critical points of the total cost function, for which the Hessian matrix becomes definite positive (Horn and Johnson 1990).

Following the above-presented analytical procedure for the three types of consequence patterns, the optimal failure probabilities in the three cases are derived. These results together with the appropriate values of expected losses in the total cost functions are presented in Table 4. In this table, $a_{1}, a_{2}=$ marginal costs of dyke-segments 1 and 2 respectively, $V, V_{1}, V_{2}$, $V_{1.1}, V_{1.2}, V_{2.2}=$ economic values in the dyke-ring as indicated in Fig. 3, and $\tau=$ present value multiplier. It is remarked that in the case of identical consequences and independent dykesegments, the last term of the expected losses $\left(P_{1} P_{2} V \tau\right)$ was neglected in the cost-optimization. The value of this term is usually negligible when compared to the other terms $\left(P_{1} V, P_{2} V\right)$, for failure probabilities in the order of $10^{-3}$ or lower. This is further explained in a latter section.

The results of Table 4 show that, in all studied cases, the optimal failure probability of any segment $i$ is proportional to the ratio of marginal costs over the economic values that will be in danger if segment $i$ fails. Comparing the results for dependent and independent dyke-sections, the optimal safety level proves to have a uniform value along fully dependent segments, which is not the case for independent segments. In reality, dyke-segments are not fully correlated, and the degree of correlation decreases as the distance between them increases. This means that the optimal protection level varies along the length of a dyke-ring. These conclusions have also been validated for dyke-rings with more than two segments, in which case the optimization formulae are similar to those of Table 4.

Table 4 Overview of optimal failure probabilities in a dyke-ring with two homogeneous sections

\begin{tabular}{cclc}
\hline & & Dependent sections $i$ & Independent sections $i$ \\
\hline $\begin{array}{c}\text { Identical } \\
\text { consequences }\end{array}$ & Expected losses & $\max \left\{P_{1}, P_{2}\right\} V \tau$ & $\left(P_{1}+P_{2}-P_{1} P_{2}\right) V \tau$ \\
& $L_{\text {system }}$ & & \\
& Optimal failure & $\left(\frac{a_{1}+a_{2}}{V \tau}, \frac{a_{1}+a_{2}}{V \tau}\right)$ & $\left(\frac{a_{1}}{V \tau}, \frac{a_{2}}{V \tau}\right)$ \\
& probabilities & & \\
Overlapping & $\left(P_{1}, P_{2}\right)_{\text {opt }}$ & & \\
consequences & Expected losses & $\max \left\{P_{1}, P_{2}\right\}\left(V_{1.1}+V_{2.2}+V_{1.2}\right) \tau$ & {$\left[P_{1} V_{1.1}+P_{2} V_{2.2}+\right.$} \\
& $L_{\text {system }}$ & & $\left.\left(P_{1}+P_{2}-P_{1} P_{2}\right) V_{1.2}\right] \tau$ \\
& Optimal failure & $\left(\frac{a_{1}+a_{2}}{\left(V_{1.1}+V_{2.2}+V_{1.2}\right) \tau}, \frac{a_{1}+a_{2}}{\left(V_{1.1}+V_{2.2}+V_{1.2}\right) \tau}\right)$ & $\left(\frac{a_{1}}{\left(V_{1.1}+V_{1.2}\right) \tau}, \frac{a_{2}}{\left(V_{2.2}+V_{1.2}\right) \tau}\right)$ \\
probabilities & $\left(P_{1}, P_{2}\right)_{\text {opt }}$ & & $\left(P_{1} V_{1}+P_{2} V_{2}\right) \tau$ \\
Non-Overlapping & Expected losses & $\max \left\{P_{1}, P_{2}\right\}\left(V_{1}+V_{2}\right) \tau$ & $\left(\frac{a_{1}}{V_{1} \tau}, \frac{a_{2}}{V_{2} \tau}\right)$ \\
consequences & $L_{\text {system }}$ & & \\
& Optimal failure & $\left(\frac{a_{1}+a_{2}}{\left(V_{1}+V_{2}\right) \tau}, \frac{a_{1}+a_{2}}{\left(V_{1}+V_{2}\right) \tau}\right)$ & \\
& probabilities & &
\end{tabular}


The formulae for optimal values of Table 4 refer to the failure probabilities of the two dykesections in the beginning of the planning period, after implementation of the optimal investment. The optimal value formulae are the design failure probabilities. These actual probabilities will increase over time due to the joint effect of climate change and structural deterioration, as shown in Fig. 5. The expected failure probability at any year $t$ after implementation of the optimal solution can be calculated as follows:

$$
P_{i . t}=P_{i .0}{ }^{\prime} e^{\alpha_{i} \eta_{i} t}
$$

\section{Applicability in the Dutch dyke-rings}

The above-presented analytical optimization approach provides insights that can assist in the determination of economically optimal design requirements of real series flood protection systems. For the Dutch dyke-rings for example, the above-presented principles allow for the determination of economically optimal protection standards using all information provided by the VNK2 project (e.g. Vergouwe and Van den Berg 2013). This section discusses the transition from a fictitious case to the optimization of real dyke-rings in the Netherlands, addressing a number of points where special attention is required. The relevant information for dyke-rings that the VNK2 project provides is summarised below:

1. Homogeneous segments $i$ in the dyke-rings, and their current failure probabilities $\left(P_{0 . \mathrm{i}}\right)$;

2. Consequence-segments $k$, i.e. dyke-segments along which failures lead to virtually identical consequences. Usually, these segments consist of several homogeneous sections;

3. Material damage and loss of life due to failure of each consequence-segment $\left(V_{k}\right)$;

4. The most probable flooding scenarios $s$, i.e. combinations of failures of consequencesegments and their probability of occurrence $\left(P_{s}\right)$.

\subsection{Choice of spatial scale}

In practice, a suitable spatial scale of optimization needs to be chosen. That implies determining along which length of the dyke-ring a single design failure probability applies. Currently,

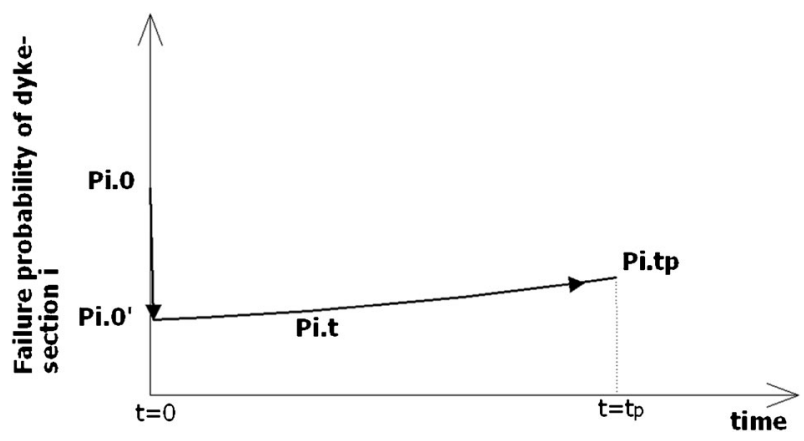

Fig. 5 Expected increase of the failure probability over time $\left(P_{i .0}=\right.$ failure probability of dyke-section $i$ before implementation of the optimal investment, $P_{i .0^{\prime}}=$ failure probability after implementation of the optimal investment, and $P_{i . \mathrm{tp}}=$ expected value of the failure probability in the end of the planning period) 
one protection standard is assigned per dyke-ring. With the VNK2-information, design values can be derived for smaller dyke-segments. The most accurate level is reached by assigning one design probability per homogeneous section, as in the above-presented fictitious example. The investment cost can then be expressed as a single function of the failure probability of a segment, as presented in the previous section. Nevertheless, such an approach is less attractive from a practical point of view, because there can be numerous homogeneous segments in a dyke-ring, in the order of 50-100, resulting in an equal number of different protection standards. The transition from one to many different protection standards within the same dyke-ring can create difficulties in other policy domains, where those standards would normally be used to facilitate decision-making, such as land use planning or determination of land prices. Hence, it would be wise to keep the number of standards per dyke-ring limited.

Determining standards on the level of consequence-segments could give a good balance of practicality and accuracy. Regarding practicality, the number of standards per dyke-ring would be reduced to 10-20, which is a considerable improvement. Accuracy is not expected to be undermined if the homogeneous sections within a consequence-segment are highly correlated. Since any failure within a consequence-segment has the same consequences, a high degree of correlation between its sections would mean that their optimal failure probabilities are about equal (see Table 4), leading to a uniform optimal failure probability along the consequencesegment. In case of weak or no correlation though, the optimal failure probability will not be uniform, hence an average value, probably less accurate, will need to be assigned. We suggest approaching this problem by defining an average function of the investment cost for each consequence-segment and its failure probability, using the line of thought of Voortman (2003). From a practical point of view, defining investment cost functions on the level of consequencesegments will allow a cost-optimization directly on this spatial scale, hence direct use of the flooding scenarios of VNK2.

\subsection{Total cost function}

The total cost in a real dyke-ring area can be expressed as in the fictitious case of Section 4, i.e. as the sum of investment costs and residual risk. Yet, two important differences, which affect the economic optimization process, must be highlighted. First, the dyke-ring needs to be considered as a series system the units of which are the consequence-segments and not the homogeneous sections. This means that the consequence-segments must be treated as homogeneous entities, with uniform failure probabilities along their length. The second difference relates to the flooding scenarios. While in the conceptual analysis the dyke-ring consisted of two segments only, a real dyke-ring consists of multiple segments, hence flooding can occur due to numerous combinations of segment failures. The probabilities of these joint failures have been determined in VNK2 as mutually exclusive scenarios (Jongejan et al. 2013). This means that the occurrence of one scenario precludes the occurrence of another. Given these deviations, the total cost can be expressed as:

$$
\mathrm{TC}=\sum_{k=1}^{n} I_{k}+\mathrm{NPV}\left[\sum_{j=1}^{m} P_{s . j} V_{s . j}\right]
$$

Where, $n=$ number of consequence-segments in the dyke-ring, $m=$ number of flooding scenarios, $I_{k}=$ investment cost in consequence-segment $k, P_{s . j}=$ probability of scenario $j, V_{s . j}=$ economic losses due to occurrence of scenario $j$, and NPV=net present value operator.

In the above equation, both investment cost and expected losses can be expressed as functions of the failure probabilities of consequence-segments $\left(P_{k}\right)$. Investment costs $I_{k}$ can 
be approximated by logarithmic functions of the failure probabilities $P_{k}$ (see Eq. 3). As for the expected losses, the probability of a scenario $j\left(P_{s, j}\right)$ is a function of the failure probabilities $P_{k}$ of the consequence-segments whose failures contribute to this scenario. The procedure to analytically derive the relationship between a scenario probability and the failure probabilities of the corresponding consequence-segments is shown here for a dyke-ring with two segments, as in the previous section. In this system, there are three possible flooding scenarios: (1) failure of segment one only, (2) failure of segment two only, (3) combined failure of segments one and two. Mutual exclusivity means that each scenario occupies a different area in a probability space of failure, as shown in the Venn diagram of Fig. 6. The coloured space of the diagram is equivalent to failure, i.e. flooding, while the white space corresponds to non-failure.

Denoting the limit state functions of segments 1 and 2 with $Z_{1}$ and $Z_{2}$, respectively, the scenario probabilities can be expressed as shown in Table 5 (third column). In order to respect mutual exclusivity of scenarios, the consequence-segments whose failures contribute to the same scenario need to be statistically independent, or partially correlated. The mathematical expression of the probabilities of scenarios given statistical independence among the contributing consequence-segments is also given in Table 5 (fourth column). For partially correlated segments, there are no analytical formulae available, but they could be approximated.

The above-presented principle for deriving the relationship between scenario probabilities and failure probabilities can be applied in systems with more segments, yet the number of scenarios increases geometrically when the number of segments increases, making the scenario probability formulae rather complex.

\subsection{Optimal failure probabilities}

Since investment cost and expected losses can be expressed as functions of the failure probabilities $P_{k}$ of the $n$ consequence-segments in a dyke-ring, the total cost is also a function of $n$ failure probabilities. Substituting Eq. 3 and the values of Table 5 into Eq. 15, the total cost function for the dyke-ring with two segments can be written as:

$$
\begin{aligned}
\mathrm{TC}= & -a_{1} \ln P_{1}+b_{1}-a_{2} \ln P_{2}+b_{2} \\
& +\operatorname{NPV}\left[\left(P_{1}-P_{1} P_{2}\right) V_{s .1}+\left(P_{2}-P_{1} P_{2}\right) V_{s .2}+P_{1} P_{2} V_{s .3}\right]
\end{aligned}
$$

Where, $V_{\mathrm{s} .1}, V_{\mathrm{s} .2}, V_{\mathrm{s} .3}=$ economic losses in flooding scenarios 1, 2, 3 respectively.

In the case of the Dutch dyke-rings, the current failure probabilities of the dykes are in the order of $10^{-4}-10^{-3}$. This implies that the terms containing the product $P_{1} P_{2}$ in the above

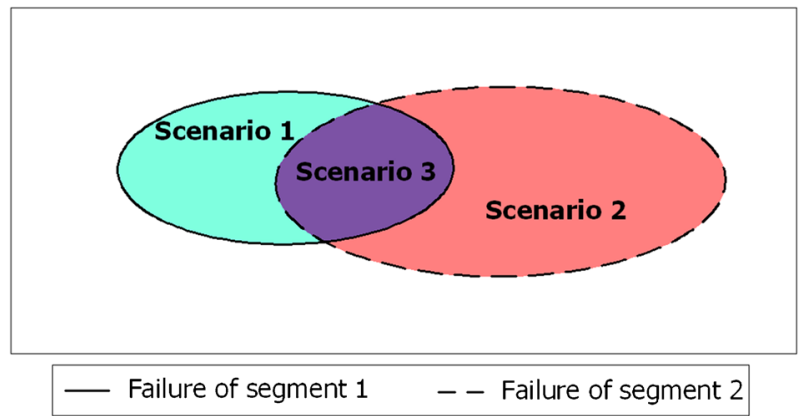

Fig. 6 Schematization of mutually exclusive flooding scenarios in a Venn diagram 
Table 5 Probabilities of flooding scenarios in system with two statistically independent elements

\begin{tabular}{llll}
\hline Scenario & Failures & $P_{s . j}$ \\
\hline 1 & Segment 1 & $P\left(Z_{1}<0\right)-P\left(Z_{1}<0 \cap Z_{2}<0\right)$ & $P_{1}-P_{1} P_{2}$ \\
2 & Segment 2 & $P\left(Z_{2}<0\right)-P\left(Z_{1}<0 \cap Z_{2}<0\right)$ & $P_{2}-P_{1} P_{2}$ \\
3 & Segments 1 and 2 & $P\left(Z_{1}<0 \cap Z_{2}<0\right)$ & $P_{1} P_{2}$ \\
\hline
\end{tabular}

equation are expected to be about 1000 times lower than the others, unless multiplied by a value $V_{\text {s.j }}$ that is 1000 times higher than corresponding values in the other terms. This effectively means that losses induced by combined failures of consequence-segments need to be more than 1000 times larger than those of individual failures in order for those terms to be meaningful. A check of the VNK2 results for all dyke-rings in the Netherlands (Rijksoverheid 2014) showed that the factor of increase of economic losses, when going from individual to combined failures, is in most dyke-rings less than 20. The highest value of this factor was detected in dyke-ring 14, where it was found to be equal to 780, a value that does not invalidate the application of this method. Since in all dyke-rings the factor of increase of economic losses is lower than 1000, the terms containing the product of two or more failure probabilities of consequence-segments can be safely omitted from the total cost function. Omitting those terms and substituting Eq. 9 into the present value operator, the total cost in the dyke-ring with two segments becomes:

$$
\mathrm{TC}=-a_{1} \ln P_{1}+b_{1}-a_{2} \ln P_{2}+b_{2}+P_{1} V_{s .1} \tau+P_{2} V_{s .2} \tau
$$

The values of $P_{1}$ and $P_{2}$ that optimize this function are:

$$
\left(P_{1}, P_{2}\right)_{\mathrm{opt}}=\left(\frac{a_{1}}{V_{s .1} \tau}, \frac{a_{2}}{V_{s .2} \tau}\right)
$$

If the economic losses in the denominators of Eq. 18 are substituted by their equivalent losses from Fig. 3, Eq. 18 proves to be identical to the formulae of Table 4. This shows that as long as the combined failures do not increase the economic losses by a factor 1000 or more, taking them into account is not going to influence the results of a cost-optimization. Given this condition, the optimal failure probabilities have been derived for a hypothetical dyke-ring with $n$ segments as follows:

$$
\left(P_{1}, P_{2}, \ldots, P_{n}\right)_{\mathrm{opt}}=\left(\frac{a_{1}}{V_{s .1} \tau}, \frac{a_{2}}{V_{s .2} \tau}, \ldots, \frac{a_{n}}{V_{s . n} \tau}\right)
$$

Where, $a_{1}, a_{2}, \ldots, a_{n}=$ marginal costs for the improvement of consequence-segments $1,2, \ldots, n$ respectively, $V_{\mathrm{s} .1}, V_{\mathrm{s} .2}, \ldots, V_{\mathrm{s} . n}=$ economic losses in scenarios that involve the individual failure of consequence-segments $1,2, . ., n$, respectively, and $\tau=$ present value multiplier.

Although the above approach can be suitable for the determination of optimal failure probabilities in the Dutch dyke-rings, we refrain from showing the results of its application, as the values of the marginal costs $\left(a_{1}, a_{2}, \ldots, a_{n}\right)$ are not readily available. In fact, investment cost functions that apply on the level of dyke-rings and dyke-stretches have been approximated (De Grace and Baarse 2011), and have been used for the determination of new protection standards with the OptimaliseRing model (see also Section 2). In order to approximate cost functions on the level of dyke-rings and dyke-stretches, local variations of costs were taken into account; yet, only $50 \%$ of the results of VNK2 were available at the time. For this reason, it is 
recommended to derive new cost functions per consequence-segment, making use of all information available through VNK2. In such an analysis, the costs for improvements against every individual failure mechanism can be explicitly taken into account (in line with Voortman 2003).

The robustness of the optimization results against possible inaccuracies of the defined cost functions can be tested by means of sensitivity analysis or a Monte Carlo probabilistic analysis. If the results are not robust enough, the consequence-segment could be divided in smaller segments, resulting in a higher number of protection standards per dyke-ring.

\section{Discussion}

\subsection{Association with mitigation and adaptation strategies}

The analysis presented in this paper can facilitate the design and inform decisions upon investments in flood prevention. Such investments are an intrinsic part of flood risk mitigation strategies. The effect of sea level rise and economic growth within the selected planning period are taken into account, making this approach suitable for use within the framework of adaptive flood prevention strategies. An indicative conceptual framework for such a strategy and how the presented analysis fits in it are shown in Fig. 7.

A quantification of the degree of uncertainty in the sea level rise and economic growth projections over time, can help in the choice of a planning period within which the selected future prospects can be considered reasonably accurate. A reasonable accuracy is achieved when possible variations of the projections within the planning period would not cause major changes in the optimization results. The selected planning period and the formal climate change projections can be then used in the economic optimization, which will determine the amounts to be invested in every segment of the flood prevention system. In the end of the planning period, an adaptation of the system to new climate change projections will need to be undertaken by repeating the same analysis.

\subsection{Global applicability}

The theory of Section 3 and the economic optimization of Section 4 are relevant for any flood prevention system, and not only the Dutch dyke-rings. In reality, flood prevention systems with non-homogeneous water retaining elements in a linear set-up can all be considered as series systems. Typical features that indicate non-homogeneity are the existence of various types of structures along the flood protection line, e.g. earthen embankments, concrete walls and storm-surge gates, or different types of load, e.g. coastal flooding from one end and river flooding from the other. The system of the lower Red River delta in Vietnam (see, e.g. Van Mai 2010), the system of New Orleans in the USA (see, e.g. Kanning 2012), or the coastal defence system of Tokyo metropolitan area in Japan (see, e.g. Hoshino et al. 2012) are good examples of systems where this approach could be applied.

\subsection{Comparison with the OptimaliseRing approach}

Comparing the economic optimization of Section 5 to the approach used for the development of the OptimaliseRing model in the Netherlands, several essential differences can be noticed. In both approaches, the dyke-ring is divided in smaller dyke-segments, and economically optimal failure probabilities are determined for them. The first difference is that, in this paper, an analytical solution is provided instead of the numerical solution provided by 


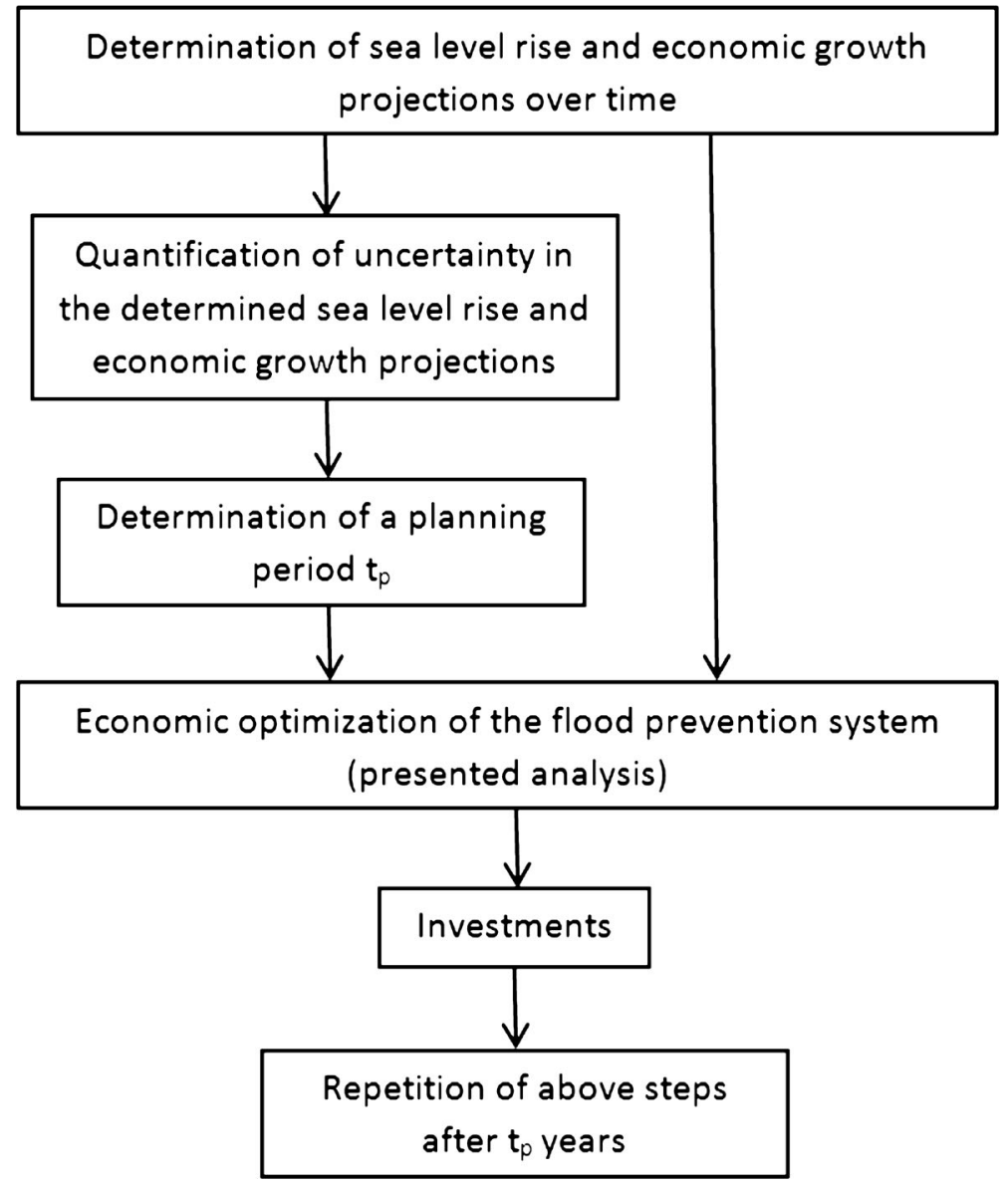

Fig. 7 Conceptual framework of an adaptive flood prevention strategy

OptimaliseRing. This allows for a better understanding of basic system optimization principles and provides easier insight into the effects of the assumptions in the final result. Secondly, dyke-segments of different lengths are optimized. In the presented analysis, optimal probabilities are determined per consequence-segment. This allows for optimal use of the flooding scenarios of VNK2, where partial correlations of failures and the length effect are taken into account. For other systems in the world, where partial correlations cannot be easily estimated, upper and lower bounds of the optimal failure probabilities are provided (see Table 4). In the OptimaliseRing approach, optimal probabilities are determined for dyke-stretches that are longer than the consequence-segments (Deltaprogramma 2013). The optimization is performed considering a full correlation of failures within the optimized dyke-stretch, leading to larger optimal probabilities than when partial correlations would be considered. Last but not least, the type of optimization is different in the two approaches. The presented analysis comprises a static optimization, where it is assumed that all investments are implemented in the beginning of a pre-defined planning period. Then, the principles of a systems design optimization are followed. This means that the variables of the total cost function are properties of the consequence-segments in a dyke-ring, i.e. structural components of the system. The 
OptimaliseRing approach comprises a dynamic optimization, where investments can be implemented in various moments throughout a time horizon of over a century, but in which every optimized dyke-stretch is treated individually, and not as the element of a system. This means that the objective function contains two variables, the failure probability of the optimized dyke-stretch and the time interval between consecutive investments.

\section{Conclusions}

The development of a new flood risk management policy that is taking place in the Netherlands, calls for new methods for the determination of protection standards. This paper proposes an economic optimization for dyke-ring areas that can assist analysts in this effort, by indicating how to accommodate three important technical factors: the existence of multiple failure mechanisms in the dyke-ring, a spatial variability of the failure probability along its length, and the possibility of occurrence of simultaneous failures in different parts of it.

The existence of multiple failure mechanisms is accommodated by taking into account the costs of reducing the probability of occurrence of each one of them when determining investment cost functions. This is an approach that has been presented in detail in previous studies.

Spatial variability of the failure probability is accommodated by treating the dyke-ring as a series system of separate dyke-segments that may interact with each other. Optimal failure probabilities can be then derived per dyke-segment. In order for such an optimization to be successful, a balance between accuracy and practicality is needed, both in the performance of the optimization process and in the use of standards in policy making. The highest accuracy can be achieved by deriving optimal failure probabilities per homogeneous dyke-section. In the Dutch case, practicality can be achieved by optimizing on the level of consequencesegments instead of on the level of homogeneous sections. This way, a substantial decrease of the number of different protection standards per dyke-ring can be achieved, and the flooding scenarios indicated in the VNK2 project can be straightforwardly used. Yet, such an upscaling approach can have an effect on the accuracy of the used investment functions. In other countries, the balance of practicality and accuracy will be probably determined by the availability of data.

The possibility of simultaneous failures in different parts of the dyke-ring can be accommodated after the determination of all possible flooding scenarios. This information is available for the Dutch dyke-rings through the VNK2 project. However, simultaneous failures do not influence the optimization result as long as they produce losses that are lower than 1000 times the losses of individual failures. In this case, which proves to be true for all dyke-rings in the Netherlands, explicit analytical formulae for the optimal failure probabilities have been suggested.

According to the derived formulae, the optimal failure probabilities of dyke-segments are proportional to their marginal investment costs, i.e. the costs for a marginal decrease of their failure probability, and inversely proportional to the losses that their failures produce. In all cases, it would be useful to check the robustness of the optimization results against inaccuracies associated with the determination of the investment cost functions.

The procedure described in this paper is intrinsic part of mitigation and adaptation strategies for flood prevention that opt for a balance between cost and safety, and is applicable worldwide. Specifically in the Netherlands, the approach can aid in the determination of new protection standards with the year 2050 as target year, i.e. for the period recommended 
by the Delta Committee (2008). Moreover, it can guide possible improvements of the already developed numerical optimization model, OptimaliseRing.

Open Access This article is distributed under the terms of the Creative Commons Attribution License which permits any use, distribution, and reproduction in any medium, provided the original author(s) and the source are credited.

\section{References}

Abrahamsen P (1997) A Review of gaussian random fields and correlation functions, Second Edition. Technical Report 917. In: Institutional archive of the Norwegian Computing Centre. Available by Norwegian Computing Centre. http://www.nr.no/en/nrpublication?query=/file/2437/Abrahamsen - A Review of Gaussian random fields and correlation.pdf

Alberts FW, Van der Most H, Hoogbergen M (2014) Synthese document Deelprogramma Veiligheid achtergrondrapport bij Delta Programma 2015. In: Publications of the Delta Programme. Available by DELTACOMMISSARIS. http://www.deltacommissaris.nl/Images/DP2 $015 \% 20 \mathrm{~B} 1 \%$ 20Synthesedocument $\% 20$ Veiligheid tcm309-358052.pdf

Arrow KJ, Cropper ML, Eads GC, Roger GN, Portney PR, Russell M, Schmalensee R, Kerry Smith V, Stavins RN (1996) Benefit-cost analysis in environmental, health, and safety regulation - a statement of principles. AEI, London

Barrieu P, Sinclair-Desgagné B (2006) On precautionary policies. Manag Sci 52(8):1145-1154

Bedford T, Cooke R (2001) Probabilistic risk analysis: foundations and methods. Cambridge University Press, Cambridge

Bischiniotis K (2013) Cost optimal river dike design using probabilistic methods. MSc thesis, Delft University of Technology

Bligh WG (1915) Dams and weirs: an analytical and practical treatise on gravity dams and weirs. American Technical Society, Chicago

Bockarjova M, Rietveld P, Verhoef ET (2012) Composite valuation of immaterial damage in flooding: Value of statistical life, value of statistical evacuation and value of statistical injury. Discussion Paper, No. 12-047/3. In: Institutional archive of the Tinbergen Institute. Available by the Tinbergen Institute. http://www. tinbergen.nl/discussionpaper/?paper=1924

Brandl H, Szabo M (2013) Hydraulic failure of flood protection dykes. In: Proceedings of the 18th International Conference on Soil Mechanics and Geotechnical Engineering, Paris, September 2-6, 2013

Cassini P (1998) Road transportation of dangerous goods: quantitative risk assessment and route comparison. J Hazard Mater 61:133-138

Central Dutch Government (2009) 2009-2015 National Water Plan. In: Publications by the Central Dutch Government. Available by the RIJKSOVERHEID. http://english.verkeerenwaterstaat.nl/english/Images/ NWP\%20english tcm249-274704.pdf

De Grace P, Baarse G (2011) Kosten van maatregelen - Informatie ten behoeve van het project Waterveiligheid 21e eeuw, In: Institutional archive of Deltares. Available by Deltares. http://www.deltaportaal.nl/ programfiles/13/programfiles/Kosten___De_Grave_en_Baarse_2011.pdf

Delta Committee (2008) Working together with water-findings of the Delta Committee. In: Publications of the Delta Committee. Available by Deltacommissie. http://www.deltacommissie. com/doc/deltareport full.pdf

Deltaprogramma (2013) Op weg naar nieuwe normen: een technisch-inhoudelijke uitwerking werkdocument Eisen aan keringen, concept van 6 september 2013. In: Archive of the Delta Programme. Available by Deelprogramma Veiligheid. https://deltaprogramma.pleio.nl/file/ download/24225892

Eijgenraam C (2005) Veiligheid tegen overstromen - Kostenbatenanalyse voor Ruimte voor de Rivier, deel 1. In: Archive of the Centraal Plan Bureau. Available by CPB. http://www.cpb.nl/sites/ default/files/publicaties/download/veiligheid-tegen-overstromen-kosten-batenanalyse-voor-ruimtevoor-de-rivier-deel-1.pdf

Folloni G, Vittadini G (2010) Human capital measurement: a survey. J Econ Surv 14(2):248-279

Gerritsen H (2005) What happened in 1953? The big flood in the Netherlands in retrospect. Philos Trans R Soc 363:1271-1291

Gollier C, Treich N (2003) Decision making under scientific uncertainty: the economics of the precautionary principle. J Risk Uncertain 27(1):77-103 
Gumbel EJ (1954) Statistical theory of extreme values and some practical applications. In: Applied Mathematics 33. Available by US National Bureau of Standards [add link]

Huizinga F (2012) The economics of flood prevention, A Dutch perspective. In: Centraal Plan bureau documents. Available by CPB. http://www.cpb.nl/en/publication/economics-flood-prevention

Horn RA, Johnson CR (1990) Matrix analysis. Cambridge University Press, Cambridge

Hoshino S, Esteban M, Mikami T, Takabatake T, Shibayama T (2013) Climate change and coastal defences in Tokyo Bay. In: Lynett P, McKee Smith j (eds) Coastal Engineering 2012. Proceedings of the 33rd International Conference on Coastal Engineering. Santander, July 2012

Joanni A, Rackwitz R (2008) Cost-benefit optimization for maintained structures by a renewal model. Reliab Eng Syst Saf 93(3):489-499

Jongejan RB (2008) How safe is safe enough? Dissertation. Delft University of Technology

Jonkman SN, Jongejan RB, Maaskant B (2011) The use of individual and societal risk criteria within the Dutch flood safety policy; nationwide estimates of societal risk and policy applications. Risk Anal 31(2):282-300

Jongejan RB, Jonkman SN, Vrijling JK (2012) The safety chain: a delusive concept. Saf Sci Issue 5(50):1299-1303

Jongejan RB, Maaskant B, Ter Horst W, Havinga F, Roode N, Stefess H (2013) The VNK2-project: a fully probabilistic risk analysis for all major levee systems in the Netherlands. In: Floods: From Risk to Opportunity. Proceedings of the $5^{\text {th }}$ International Conference on Flood Management. Tokyo, September 2011

Jongejan RB, Maaskant B (2013) Applications of VNK2, a fully probabilistic risk analysis for all major levee systems in The Netherlands. In: Klijn F, Schwekendiek T (eds) Comprehensive flood risk management: research for policy and practice. Proceedings of the $2^{\text {nd }}$ European Conference in Flood Risk Management. Rotterdam, November 2012. Taylor \& Francis Group, London

Jonkman SN, Van Gelder PHAJM, Vrijling JK (2003) An overview of quantitative risk measures for loss of life and economic damage. J Hazard Mater 99:1-30

Jonkman SN (2007) Loss of life estimation in flood risk assessment. Dissertation. Delft University of Technology

Kanning W (2012) The weakest link — spatial variability in the Piping Failure Mechanism of Dikes. Dissertation. Delft University of Technology

Kind JM (2013) Economically efficient flood protection standards for the Netherlands. J Flood Risk Manag. doi: $10.1111 /$ jfr3.12026

Mai Van C (2010) Probabilistic design of coastal defences in Vietman. Dissertation. Delft University of Technology

Möllmann AFD, Vermeer PA (2007) Reliability analysis of a dike failure. In: Proceedings of the 18th European Young Geotechnical Engineers' Conference. Ancona, June 2007

Nowak AS, Collins KR (2000) Reliability of structures. McGraw-Hill, Boston

Pearce DW, Nash CA (1983) The social appraisal of projects: a text in cost-benefit analysis. Macmillan, London and Basingstoke

Petty W (1690) Political arithmetik, or a discourse concerning the extent and value of lands, people, buildings. Cambridge University Press, Cambridge

Rijksoverheid (2014) VNK2 reports online http://www.helpdeskwater.nl/onderwerpen/waterveiligheid/ programma'-projecten/veiligheid-nederland/publicaties/dijkringrapporten/overzichtspagina'/ dijkringrapporten/ Cited on 2 Dec 2014

Schweckendiek T, Kanning W (2009) Updating piping probabilities with survived historical loads. In: Vrijling J.K., Van Gelder PHAJM, Proske D (eds) Proceedings of the 7th International Probabilistic Workshop. Delft, November 25-26, 2009

Schweckendiek T, Vrouwenvelder ACWM, Calle E, Kanning W, Jongejan RB (2013) Target reliabilities and partial factors in the Netherlands. In: Arnold P, Fenton GA, Hicks MA (eds) Modern geotechnical design codes of practice. Ios, Amsterdam

Sellmeijer JBA (1988) On the mechanism of piping under impervious structures. Delft University of Technology, Dissertation

Slovic P (1999) Trust, emotion, sex, politics, and science: surveying the risk-assessment battlefield. Risk Anal 19(4):689-701

Stewart S (2008) Calculus-Early Transcendentals 6th Edition. Thomson ISBN-13: 978-0-495-01166-8 [add place of publication]

Ten Brinke WBM, Bannink BA (2004) Risico's in bedijkte termen, een thematische evaluatie van het Nederlandse veiligheidsbeleid tegen overstromen. In: Archive of RIVM Available by RIVM. http://www. rivm.nl/dsresource?objectid=rivmp: $15138 \&$ type $=$ org\&disposition=inline\&ns_nc $=1$

Tsimopoulou V (2010) Probabilistic design of breakwaters in shallow, hurricane-prone areas. MSc thesis. Delft University of Technology

Van Dantzig D (1956) Economic decision problems for flood prevention. Econometrica 24:276-287 
Van Manen SE, Brinkhuis M (2005) Quantitative flood risk assessment for polders. Reliab Eng Syst Saf 90:229-237

Vergouwe R, Van den Berg MCJ (2013) Veiligheid Nederland in Kaart 2: Overstromingsrisico dijkring 16 Alblasserwaard en de Vijfheerenlanden. In: VNK project office reports. Available by RIJKSOVERHEID. http://helpdeskwater.nl/publish/pages/33405/d3_dijkringrapport_16_def.pdf

VNK2 project office (2012) Flood Risk in the Netherlands VNK2: the method in brief, In: VNK project office. Available by RIJKSOVERHEID. http://www.helpdeskwater.nl/publish/pages/27082/vnk_nader_verklaard uk-lr 1.pdf

Voortman HG (2003). Risk-based design of large scale flood defence systems. Dissertation. Delft University of Technology

Vrijling JK, Van Beurden IJCA (1991) Sea level rise: A probabilistic design problem. In: Proceedings of the International Coastal Engineering Conference. New York, 1991. ASCE 1160-1171

Vrijling JK, Van Gelder PHAJM (1997) Societal risk and the concept of risk aversion, In: Guedes Soares C (ed) Advances in Safety and Reliability. Proceedings Of the ESREL Conference, Lisbon, 17-20 June, 1997. Pergamon, Oxford (1): 45-52

Vrouwenvelder ACWM, Struik P (1991) Safety philosophy for dike design in The Netherlands. In: Proceedings of the International Coastal Engineering Conference. New York, 1991. ASCE 1254-1267.

Vrouwenvelder ACWM (2006) Spatial effects in reliability analysis of flood protection systems. In: Proceedings of the 2nd IFED Forum. Lake Louise, April 2006

Walton TL (2000) Distributions for storm surge extremes. Ocean Eng 27:1279-1293. doi:10.1016/S00298018(99)00052-9 